\section{Kidney \\ Blood Pressure \\ Research}

Original Paper

\title{
Solitary Functioning Kidney in Children - A Follow-Up Study
}

\author{
Gabriel Kolvek ${ }^{a, b} \quad$ Ludmila Podracka $^{a, b} \quad$ Jaroslav Rosenberger ${ }^{b}$ Roy E. Stewart \\ Jitse P. van Dijk ${ }^{\mathrm{b}, c}$ Sijmen A. Reijneveld ${ }^{c}$
}

aPaediatric Department, Faculty of Medicine, Safarik University; bGraduate School Kosice Institute for Society and Health, Safarik University, Kosice, Slovak Republic; 'University of Groningen, University Medical Center Groningen, Department of Community \& Occupational Health, Groningen, The Netherlands

\section{Key Words}

Albuminuria $\bullet$ Children $•$ Glomerular filtration rate $•$ Hypertension $•$ Solitary kidney

\begin{abstract}
Background/Aims: This study aims to assess the cumulative incidence of elevated albuminuria, hypertension and decreased estimated glomerular filtration rate (eGFR) to identify possible renal injury in children with SFK. Methods: Forty-two children with SFK (23 boys; 27 congenital) were included in a prospective follow-up study. Blood pressure, albuminuria and eGFR were assessed repeatedly and the cumulative incidence rate of various forms of renal injury, overall and by type of etiology, were evaluated. Finally, renal injury-free survival was analyzed. Results: Mean follow-up was until age 11.3 years (SD 6.3 years). During follow-up, 16 (38.1\%) patients met the criteria for renal injury, defined as hypertension $(10 ; 23.8 \%)$, severely increased albuminuria $(3 ; 7.1 \%)$ and a significantly impaired eGFR $\left(<60 \mathrm{ml} / \mathrm{min} / 1.73 \mathrm{~m}^{2}\right)(5 ; 11.9 \%)$ and/ or use of antihypertensive or antiproteinuric medication $(11 ; 26.2 \%)$. Children with CAKUT in SFK had a significantly higher incidence of renal injury. The median time to develop renal injury was 12.8 years. Conclusion: A substantial proportion of children with SFK develop renal injury during childhood, especially those with CAKUT in the SFK. Therefore, close follow-up of albuminuria, blood pressure and eGFR are warranted to identify chronic kidney disease in its early stages.
\end{abstract}

Copyright $@ 2014$ S. Karger AG, Basel

\section{Introduction}

In 1988 Brenner et al. described their ground-breaking hyperfiltration hypothesis in rats with subtotal renal mass reduction [1, 2], suggesting that a reduction in the number of functioning nephrons leads to haemodynamic changes in the residual glomeruli and 


\section{Kidney Blood Pressure Research}

ultimately results in glomerular sclerosis $[3,4]$. Several post-mortem studies as well as clinical observations of hypertensive patients also supported the hyperfiltration hypothesis in humans [5-8]. Nephron endowment at birth, which varies widely from 200,000 to more than 2,500,000 per kidney [9-11], may thus be understood as a determining factor of kidney survival. Unfortunately, measures or even estimates of the nephron number in vivo are currently impossible.

A solitary functioning kidney (SFK) is a unique model of renal-mass reduction; thus, consequences due to hyperfiltration may be expected. Paradoxically, living-kidney donors are frequently shown to have stable renal function over more than 25 years after nephrectomy [12-14]. In children with SFK controversies regarding renal function exist. Some studies support favorable outcomes, which is the opposite of what might be expected according to the Brenner hypothesis $[15,16]$, while others do not, both in children after nephrectomy $[17,18]$ and in children with congenital SFK [19]. Follow-up studies are scarce. In 2009 Sanna-Cherchi et al. presented their renal survival analysis in patients born with one kidney, showing that $50 \%$ of these patients needed dialysis by the age of 30 years old, a result which highlighted potential subclinical renal defects [20]. Recent findings of Westland et al. showed a median time to renal injury of 14.8 years (14.9 years for congenital SFK) [21]. Due to differences in sampling and design, however, these findings cannot be fully compared, and further evidence on this issue is lacking.

Until the measurement of the number of nephrons in vivo is possible, only observational longitudinal follow-up studies may shed further light on the long-term prognosis for children with SFK. Our aim was to add to this evidence by studying Slovak children with SFK using a methodology that enables comparison with the already available evidence. KDIGO experts have recently published a consensus guideline defining 'albuminuria' as moderately ( $>30 \mathrm{mg} / 24$ hours) or severely increased (>300mg/24hours) and highlighted adverse consequences in people with albumin excretion and/or GFR $<60 \mathrm{ml} / \mathrm{min} / 1.73 \mathrm{~m}^{2}$ irrespective of the etiology or duration of reduced kidney function [22]. Thus, this study aims to assess the cumulative incidence of elevated albuminuria and hypertension and decreased GFR in SFK children in order to identify possible renal injury during childhood using a similar methodology as Westland et al. [21].

\section{Patients and methods}

\section{Patients}

All children with SFK who were followed at a tertiary nephrology centre (Children's Faculty Hospital, Kosice, Slovakia) were included in this prospective follow-up study (N=47). SFK was defined as the unilateral absence of a (functioning) kidney at ultrasound, confirmed by renal scintigraphy. Children with an acquired SFK as a result of malignancy ( $n=5$; Wilms' tumor: 3 , renal cell carcinoma: 1, neuroblastoma: 1 ) were excluded because of potential confounding effects due to the use of nephrotoxic chemotherapy. Thus, 42 patients were eligible for the analyses.

To identify potential differences between two groups of SFK, patients were divided into two categories: congenital SFK or acquired SFK. A congenital SFK can be due to unilateral agenesis/aplasia or a multicystic dysplasia. Children who underwent a unilateral nephrectomy were classified as those with acquired SFK. Indications for nephrectomy are shown in Table 1. To study the additional effect of congenital anomalies of kidneys and urinary tract (CAKUT), patients were also subdivided into two more categories: "CAKUT +" (i.e. CAKUT in SFK) and "CAKUT -" based on the presence or absence of CAKUT as diagnosed by ultrasound and a DMSA scan. Seven (58.3\%) out of 12 patients had vesicouretheral reflux, 3 (25.0\%) had dysplasia and 2 $(16.7 \%)$ had hydronephrosis in the SFK.

\section{Measurements}

Blood pressure was measured by the auscultatory method with an appropriate cuff size. To minimize the effect of stress, the lowest of three measurements was used. Hypertension was defined as systolic and/ or diastolic blood pressure $\geq 95^{\text {th }}$ percentile, corrected for age, gender, and height [23]. Severely increased 


\section{Kidney \\ Blood Pressure Research}

albuminuria was defined using the KDIGO terminology as urinary albumin excretion $>300 \mathrm{mg} / 24$ hours in timed collected urine samples (24 hours) [22, 24]. Estimated glomerular filtration rate (eGFR) was calculated using the original Schwartz formula (eGFR=k x height/serum creatinine) [25] as the Jaffe method was used for the measurement of creatinine. Thus a new recently published Schwartz formula was not fitting suitably as it is recommended for enzymatic measurement of creatinine [26]. A significantly impaired eGFR was defined as an eGFR $<60 \mathrm{ml} / \mathrm{min} / 1.73 \mathrm{~m}^{2}$ (chronic kidney disease stage 3-4). Renal injury was defined as persistent presence of any of the following: hypertension and/or severely increased albuminuria and/or a significantly impaired eGFR and/or use of antihypertensive or antiproteinuric medication [21]. Angiotensin converting enzyme inhibitors were indicated if hypertension was present as defined in the fourth report on the diagnosis, evaluation, and treatment of high blood pressure in children and adolescents [23] or if albuminuria reached severely increased level according to the KDIGO definition [22].

\section{Statistics}

We first assessed the etiology of the cases of SFK and the background characteristics of the sample overall and by type of etiology (congenital vs. acquired). Second, we assessed the cumulative incidence rate of various forms of renal injury, overall and by type of etiology. Finally, we performed an analysis of renal injury-free survival, and the degree to which this was determined by type of etiology and CAKUT in SFK. Chi-square tests (categorical variables) were used to assess the statistical significance of the differences between groups. Statistical significance was set at a p-level of 0.05. SPSS 20.0, and SAS 9.2 was used for the statistical analyses.

\section{Results}

\section{Patients}

The data concerned 42 patients (23 boys) with SFK, of whom 27 with a congenital SFK (64.3\%); data regarding the etiology is presented in Table 1. The SFK in our sample was identified mainly accidentally during an abdominal ultrasound while 10 (23.8\%) patients were referred when they were already showing signs of renal injury. In 5 patients $(11.9 \%)$ the SFK was identified by neonatal ultrasound. The mean age at last follow-up was 11.3 years (standard deviation, SD: 6.3 years). The difference in age between children with congenital and acquired SFK was not significant (11.1 vs. 11.6 years, $p=0.65$ ). CAKUT+ was present in $12(28.6 \%)$ patients, without a statistically significant difference between the congenital and acquired group $(\mathrm{p}=0.80)$.

\section{Renal injury}

Table 2 shows that $16(38.1 \%)$ patients met the criteria for renal injury-defined as a persistent presence of hypertension and/or severely increased albuminuria and/or a significantly impaired glomerular filtration rate $(<60 \mathrm{ml} /$ $\mathrm{min} / 1.73 \mathrm{~m} 2$ ) and/or the use of antihypertensive or antiproteinuric medication - at a median age of 11.0 years. The occurrence of renal injury was similar in the congenital and acquired SFK group $(\mathrm{p}=0.39$; Table 2), but differed between the CAKUT+ and CAKUT- children $(\mathrm{p}<0.01$; Table 3). Hypertension, severely increased albuminuria and a significantly impaired eGFR were found during follow-up in $10(23.8 \%), 3(7.1 \%)$ and $5(11.9 \%)$ children, respectively. Antihypertensive or antiproteinuric medication was used by $11(26.2 \%)$ patients. Mean eGFR at the last follow-up was $83.2 \mathrm{~mL} / \mathrm{min} / 1.73 \mathrm{~m} 2$ (SD $26.4 \mathrm{~mL} / \mathrm{min} / 1.73 \mathrm{~m} 2$ ). None of the rates of these types of injury differed with statistical significance by etiology, but the cumulative incidence rates of hypertension, severely increased albuminuria and significantly impaired eGFR were significantly higher in CAKUT+
Table 1. Etiology of solitary functioning kidney (SFK)

\begin{tabular}{lr}
\hline Type of SFK & $\begin{array}{r}\text { Number of } \\
\text { patients (\%) }\end{array}$ \\
\hline Congenital & $27(64.3)$ \\
Unilateral renal agenesis & $15(35.7)$ \\
Multicystic dysplastic kidney & $12(28.6)$ \\
Acquired & $15(35.7)$ \\
Vesicoureteral reflux & $2(4.7)$ \\
Ureteropelvic junction obstruction & $6(14.2)$ \\
Ureterovesical junction obstruction & $2(4.7)$ \\
Renal artery stenosis & $2(4.7)$ \\
Miscellaneous & $3(7.1)$ \\
Total & $42(100.0)$ \\
\hline
\end{tabular}




\section{Kidney Blood Pressure Research}

Table 2. Cumulative incidence rate of renal injury, total and by type, in solitary functioning kidney (SFK) patients

\begin{tabular}{lcccc}
\hline & SFK $(\mathrm{N}=42)$ & Congenital-SFK $(\mathrm{n}=27)$ & Acquired-SFK (n=15) & $\mathrm{P}$ \\
\hline Renal injury, total & $16(38.1)$ & $9(33.3)$ & $7(46.7)$ & 0.39 \\
Hypertension & $10(23.8)$ & $5(18.5)$ & $5(33.3)$ & 0.28 \\
Severely increased albuminuria & $3(7.1)$ & $2(7.4)$ & $1(6.7)$ & 0.93 \\
eGFR<60ml/min/1.73m² & $5(11.9)$ & $3(11.1)$ & $2(13.3)$ & 0.83 \\
Anti-hypertensive/ -proteinuric medication & $11(26.2)$ & $6(22.2)$ & $5(33.3)$ & 0.43 \\
\hline
\end{tabular}

eGFR - estimated glomerular filtration rate. Percentages per type add up to more than the percentage under total as children may have more types of injury simultaneously.

Table 3. Cumulative incidence rate of renal injury, total and by type, in solitary functioning kidney (SFK) patients

\begin{tabular}{|c|c|c|c|c|}
\hline & SFK $(N=42)$ & CAKUT $+(n=12)$ & CAKUT - $(n=30)$ & $\mathrm{P}$ \\
\hline Renal injury, total & $16(38.1)$ & $10(83.3)$ & $6(20.0)$ & $<0.01$ \\
\hline Hypertension & $10(19.0)$ & $5(41.7)$ & $5(16.7)$ & 0.14 \\
\hline Severely increased albuminuria & $3(7.1)$ & $3(25.0)$ & $0(0.0)$ & $<0.01$ \\
\hline $\mathrm{eGFR}<60 \mathrm{ml} / \mathrm{min} / 1.73 \mathrm{~m}^{2}$ & $5(11.9)$ & $5(41.7)$ & $0(0.0)$ & $<0.01$ \\
\hline Anti-hypertensive/-proteinuric medication & $11(26.2)$ & $7(58.3)$ & $4(13.3)$ & $<0.05$ \\
\hline
\end{tabular}

versus CAKUT-; Tables 2 and 3 , respectively. In the entire cohort, 2 (4.8\%) children developed endstage renal disease, at 6 and 16 years of age, both with significant CAKUT (namely dysplasia) in the SFK.

Kaplan-Meier analysis showed a median time to develop renal injury of 12.8 years. The proportion that remained free from renal injury at the end of 10 and 15 years was $70.8 \%$ and $43.5 \%$, respectively (Figure 1). For the congenital SFK group assessed separately, the median time to develop renal injury was 13.3 years $(\mathrm{p}=0.91$; congenital versus

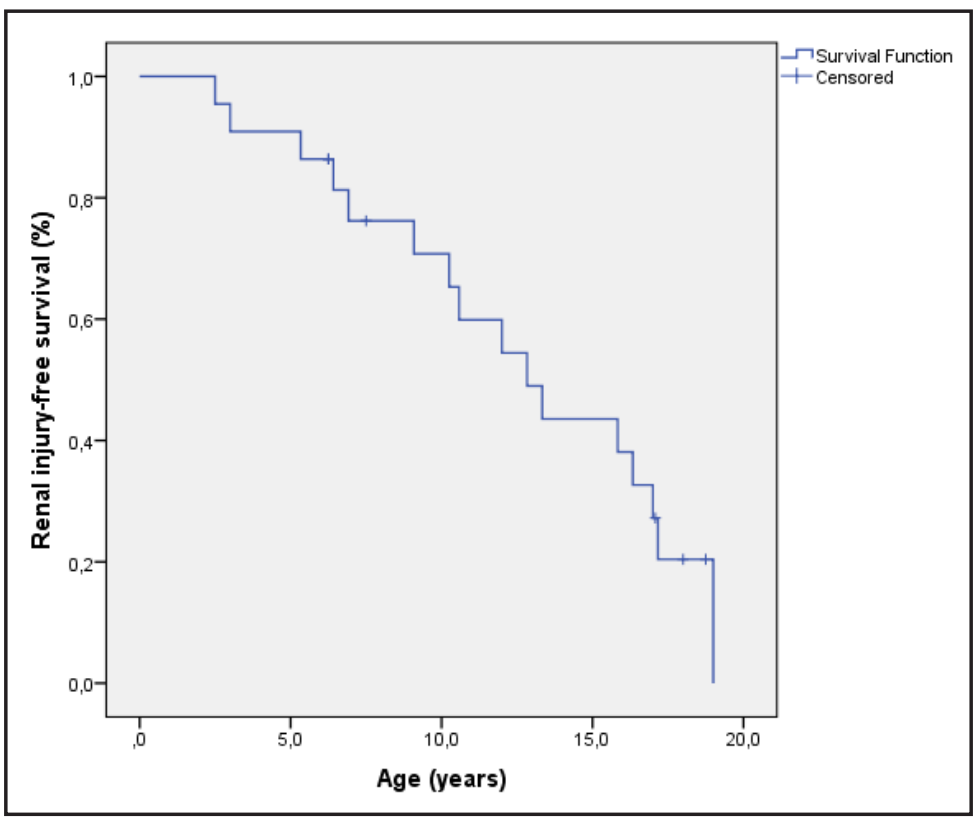

Fig. 1. Renal injury-free survival in children with a solitary functioning kidney. acquired). While the median time to develop renal injury was similar between the types of SFK ( $p=0.91)$, CAKUT+ patients had a borderline significant shorter median time to develop renal injury than did CAKUT- patients (19.0 years vs. 10.6 years $\mathrm{p}=0.06$ ).

\section{Discussion}

This study demonstrates that a substantial proportion of children (38.1\%) with SFK developed renal injury at the median age of 11.0 years. The estimated GFR decreased below $60 \mathrm{ml} / \mathrm{min} / 1.73 \mathrm{~m} 2$ in $11.9 \%$ of patients, and $4.8 \%$ of the patients from our cohort reached end-stage renal disease during childhood. 


\section{Kidney Blood Pressure Research}

Our findings are in line with a recent study by Westland et al., who showed that in a large Dutch sample of 407 children $37 \%$ of SFK patients developed renal injury at a mean age of 6.4 (SD 5.9) years [21]. Our study is showing a similar proportion (38.1\%) at a higher median age using more strict inclusion criteria (severely increased albuminuria). We identified renal injury in both the congenital and acquired SFK group. In contrast, Jaoude et al. found a significant difference favoring congenital SFK, which they interpreted as indicating a better functional adaptation in that etiological category [17]. Furthermore, a significant influence of CAKUT on renal injury prognosis was found even in our small sample in line with Westland's et al. findings.

Two children in our cohort (4.8\%) developed ESRD at the age of 6 and 16 years which both had significant CAKUT (namely dysplasia) in the remaining kidney. Interestingly, SannaCherchi et al. found that at a higher age, i.e. 30 years, half of children with congenital SFK had developed ESRD [20]. They explained their findings by subclinical defects in the SFK as well as by selection bias. A direct comparison with our sample is not possible due to our shorter follow-up period, but a clear tendency of increasing renal injury with age is visible. Thus our study is suitably filling the gap between young patient's in Westland's sample and significantly older patients in the sample of Sanna-Cherchi et al.

During the past decades an increasing number of studies have supported the excellent outcomes of adult kidney donors $[12-14,27]$. These are nowadays frequently cited as an argument for the good outcome of SFK patients in general. However, in our opinion studies on living-kidney donors cannot be compared with nephrectomised children because of several differences. First, hyperfiltration likely has a more serious impact if the nephrectomy is performed during childhood $[18,28,29]$. Second, life expectancy in children is more likely to exceed the periods of follow-up in the studies so far conducted. Thus, changes could possibly develop later, after 30 years, as proposed by Brenner and Mackenzie and recently by Siomou et al. $[4,8]$. Third, the selection of apparently healthy donors may in fact imply the selection of patients with an above-average number of nephrons [30].

It is questionable whether findings on patients from mostly western countries allow direct comparison with the Slovak population. In this context Czech children may be the best fit. In 1991 Janda et al. reported on 40 patients with SFK (23 with agenesis, at a mean age of 11.9, SD 4.3; and 17 after nephrectomy with a mean age of 7.8, SD 3.9) in threequarters of whom microalbuminuria was present. No child suffered from renal insufficiency during follow-up [31]. In 2006 Seeman et al. reported good outcomes regarding a subgroup of patients with unilateral renal agenesis and no evidence of scars. When children of a comparable age with concomitant anomaly in SFK were tested, however, signs of injury were confirmed [32]. Unfortunately, Seeman's study was cross-sectional at a median age of 10.0 years, which hampers inferences on further prognosis. As shown by the ItalKid registry, the probability of kidney survival sharply declines during puberty, and the same effect might be expected in children with SFK; this tendency is also visible in our data, as presented in Figure 1.

\section{Strengths and limitations}

The strength of our study is that data on continued follow-up in a tertiary nephrology centre is presented. Albuminuria, a sensitive marker of kidney injury was prospectively followed what has been only rarely done so far in SFK patients. The main limitation is the limited number of patients included, which limited the power of our study. Second, our cohort for a significant part represents children with SFK who were referred because they showed symptoms (23.8\%), therefore, our findings may overestimate the effects of SFK due to an overrepresentation of poorly faring children. A full community study might solve this issue but would obviously be very expensive due to the rare nature of SFK in children.

\section{Implications}

Our results support the need for a close follow-up of SFK patients, especially those with CAKUT in the SFK, as suggested by Corbani and Westland and many others [21, 33, 


\section{Kidney \\ Blood Pressure Research}

34], since at least a portion of these patients have an unfavorable prognosis and should be monitored more closely. As the accuracy of the creatinine-based equations is limited when GFR decreases, follow-up using a combined serum cystatin C/creatinine-based equation is recommended, if available $[35,36]$. Investigation of SFK in deceased individuals is advised in order to allow a retrospective classification of SFK patients into groups according to the number of nephrons per kidney.

\section{Conclusion}

A substantial proportion of children with SFK develop renal injury during childhood, especially those with CAKUT in the SFK. A close follow-up and regular monitoring of albuminuria, blood pressure and eGFR seems warranted to identify poorly faring children early and to postpone the progression of chronic kidney disease by antihypertensive or antiproteinuric medication.

\section{Disclosure Statement}

The authors of this manuscript state that they do not have any conflict of interests and nothing to disclose.

\section{Acknowledgements}

This work was supported by the project 'Centre for Excellent Research of Atherosclerosis and its Complications - Myocardial Infarction and Stroke', Operational Program of Research and Development financed by the European Fund for Regional Development and by the Slovak Research and Development Agency under contract no. APVV-0220-10.

\section{References}

1 Brenner BM, Garcia DL, Anderson S: Glomeruli and blood pressure. Less of one, more the other? Am J Hypertens 1988;1:335-347.

-2 Hostetter TH, Olson JL, Rennke HG, Venkatachalam MA, Brenner BM: Hyperfiltration in remnant nephrons: a potentially adverse response to renal ablation. Am J Physiol 1981;241:F85-F93.

3 Brenner BM: Nephron adaptation to renal injury or ablation. Am J Physiol 1985;249:F324-F337.

4 Brenner BM, Mackenzie HS: Nephron mass as a risk factor for progression of renal disease. Kidney Int Suppl 1997;63:S124-S127.

>5 Hoy WE, Hughson MD, Singh GR, Douglas-Denton R, Bertram JF: Reduced nephron number and glomerulomegaly in Australian Aborigines: a group at high risk for renal disease and hypertension. Kidney Int 2006;70:104-110.

6 Keller G, Zimmer G, Mall G, Ritz E, Amann K: Nephron number in patients with primary hypertension. N Engl J Med 2003;348:101-108.

7 Hughson MD, Douglas-Denton R, Bertram JF, Hoy WE: Hypertension, glomerular number, and birth weight in African Americans and white subjects in the southeastern United States. Kidney Int 2006;69:671-678.

-8 Siomou E, Giapros V, Papadopoulou F, Pavlou M, Fotopoulos A, Siamopoulou A: Growth and function in childhood of a normal solitary kidney from birth or from early infancy. Pediatr Nephrol 2014;29:249-256.

-9 Bertram JF, Douglas-Denton RN, Diouf B, Hughson MD, Hoy WE: Human nephron number: implications for health and disease. Pediatr Nephrol 2011;26:1529-1533.

10 Hoy WE, Rees M, Kile E, Mathews JD, Wang Z: A new dimension to the Barker hypothesis: low birthweight and susceptibility to renal disease. Kidney Int 1999;56:1072-1077. 


\section{Kidney \\ Blood Pressure Research}

11 Hughson M, Farris AB,3rd, Douglas-Denton R, Hoy WE, Bertram JF: Glomerular number and size in autopsy kidneys: the relationship to birth weight. Kidney Int 2003;63:2113-2122.

12 Goldfarb DA, Matin SF, Braun WE, Schreiber MJ, Mastroianni B, Papajcik D, Rolin HA, Flechner S, Goormastic M, Novick AC: Renal outcome 25 years after donor nephrectomy. J Urol 2001;166:2043-2047.

13 Hakim RM, Goldszer RC, Brenner BM: Hypertension and proteinuria: long-term sequelae of uninephrectomy in humans. Kidney Int 1984;25:930-936.

14 Najarian JS, Chavers BM, McHugh LE, Matas AJ: 20 Years Or More of Follow-Up of Living Kidney Donors. Lancet 1992;340:807-810.

15 Robitaille P, Mongeau JG, Lortie L, Sinnassamy P: Long-term follow-up of patients who underwent unilateral nephrectomy in childhood. Lancet 1985;1:1297-1299.

-16 Simon J, Zamora I, Mendizabal S, Castel V, Lurbe A: Glomerulotubular balance and functional compensation in nephrectomized children. Nephron 1982;31:203-208.

$\checkmark 17$ Abou Jaoude P, Dubourg L, Bacchetta J, Berthiller J, Ranchin B, Cochat P: Congenital versus acquired solitary kidney: is the difference relevant? Nephrol Dial Transplant 2011;26:2188-2194.

18 Argueso LR, Ritchey ML, Boyle ET,Jr, Milliner DS, Bergstralh EJ, Kramer SA: Prognosis of children with solitary kidney after unilateral nephrectomy. J Urol 1992;148:747-751.

19 Argueso LR, Ritchey ML, Boyle ET,Jr, Milliner DS, Bergstralh EJ, Kramer SA: Prognosis of patients with unilateral renal agenesis. Pediatr Nephrol 1992;6:412-416.

-20 Sanna-Cherchi S, Ravani P, Corbani V, Parodi S, Haupt R, Piaggio G, Innocenti ML, Somenzi D, Trivelli A, Caridi G, Izzi C, Scolari F, Mattioli G, Allegri L, Ghiggeri GM: Renal outcome in patients with congenital anomalies of the kidney and urinary tract. Kidney Int 2009;76:528-533.

-21 Westland R, Kurvers RA, van Wijk JA, Schreuder MF: Risk factors for renal injury in children with a solitary functioning kidney. Pediatrics 2013;131:e478-e485.

22 Kidney Disease: Improving Global Outcomes clinical practice guidelines for the Evaluation and Management of Chronic Kidney Disease. Kidney Int 2013;3:S15-S18.

23 National High Blood Pressure Education Program Working Group on High Blood Pressure in Children and Adolescents. The fourth report on the diagnosis, evaluation, and treatment of high blood pressure in children and adolescents. Pediatrics 2004;114:S555-S576.

-24 Mogensen CE, Vestbo E, Poulsen PL, Christiansen C, Damsgaard EM, Eiskjaer H, Frøland A, Hansen KW, Nielsen S, Pedersen MM: Microalbuminuria and potential confounders. A review and some observations on variability of urinary albumin excretion. Diabetes Care 1995;18:572-581.

-25 Schwartz GJ, Haycock GB, Edelmann CM,Jr, Spitzer A: A simple estimate of glomerular filtration rate in children derived from body length and plasma creatinine. Pediatrics 1976;58:259-263.

-26 Schwartz GJ, Muñoz A, Schneider MF, Mak RH, Kaskel F, Warady BA, Furth SL: New equations to estimate GFR in children with CKD. J Am Soc Nephrol 2009;20:629-637.

27 Saran R, Marshall SM, Madsen R, Keavey P, Tapson JS: Long-term follow-up of kidney donors: a longitudinal study. Nephrol Dial Transplant 1997;12:1615-1621.

28 Celsi G, Jakobsson B, Aperia A: Influence of age on compensatory renal growth in rats. Pediatr Res 1986;20:347-350.

29 Okuda S, Motomura K, Sanai T, Tsuruda H, Oh Y, Onoyama K, Fujishima M: Influence of age on deterioration of the remnant kidney in uninephrectomized rats. Clin Sci Lond 1987;72:571-576.

30 Chevalier RL: When is one kidney not enough? Kidney Int 2009;76:475-477.

-31 Janda J, Stolcova P, Sikut M, Feber J: The solitary kidney in children and adolescents. Morphologic and functional characteristics. Cesk Pediatr 1991;46:195-199.

-32 Seeman T, Patzer L, John U, Dusek J, Vondrák K, Janda J, Misselwitz J: Blood pressure, renal function, and proteinuria in children with unilateral renal agenesis. Kidney Blood Press Res 2006;29:210-215.

-33 Corbani V, Ghiggeri GM, Sanna-Cherchi S: 'Congenital solitary functioning kidneys: which ones warrant follow-up into adult life?' Nephrol Dial Transplant 2011;26:1458-1460.

34 Shirzai A, Yildiz N, Biyikli N, Ustunsoy S, Benzer M, Alpay H: Is microalbuminuria a risk factor for hypertension in children with solitary kidney? Pediatr Nephrol 2014;29:283-288.

-35 Wasilewska A, Zoch-Zwierz W, Jadeszko I, Porowski T, Biernacka A, Niewiarowska A, KorzenieckaKozerska A: Assessment of serum cystatin C in children with congenital solitary kidney. Pediatr Nephrol 2006;21:688-693.

-36 Westland R, Abraham Y, Bokenkamp A, Stoffel-Wagner B, Schreuder MF, van Wijk JA: Precision of estimating equations for GFR in children with a solitary functioning kidney: the KIMONO study. Clin J Am Soc Nephrol 2013;8:764-772. 